\title{
Effect of Titanium on FOX-7 - A DFT Treatment
}

\section{Lemi Türker}

Department of Chemistry, Middle East Technical University, Üniversiteler, Eskişehir Yolu No: 1, 06800 Çankaya/Ankara, Turkey; e-mail: 1turker@gmail.com; 1turker@metu.edu.tr

\section{Abstract}

FOX-7 is a push-pull type conjugated system which attracts attention as an insensitive high energy material. The present study considers its titanium composite within the restrictions of density functional theory at the levels of B3LYP/LANL2DZ and B3LYP/6$311++\mathrm{G}(2 \mathrm{df}, 2 \mathrm{p})$. The results indicate that the titanium atom transfers some electron population to the organic component, thus forces one of the $\mathrm{N}-\mathrm{O}$ bonds to rupture. Various structural, quantum chemical and UV-VIS spectral data are collected and discussed.

\section{Introduction}

Titanium, previously called "menaccine" obtained from menaccite or menacconite in the last quarter of the 18th century (now that ore is known as ilmenite $\left.\left(\mathrm{FeO} . \mathrm{TiO}_{2}\right)\right)[1,2]$ is a ductile and malleable metal. It is resistant to corrosion, but when heated burns in oxygen to form $\mathrm{Ti}_{2} \mathrm{O}_{3}$ and in nitrogen TiN. It gets mainly the oxidation states of II-IV.

Titanium is used in fountain fireworks as admixture of various energetic materials [3]. The use of the pyrotechnic, titanium/potassium perchlorate $\left(\mathrm{Ti} / \mathrm{KClO}_{4}\right)$, for hot wire actuation applications increased during the early 1970's as a response to the decision not to use primary explosives. $\mathrm{Ti} / \mathrm{KClO}_{4}$ is static sensitive in the bulk but there is reduced static sensitivity when loaded in a device. Also, its other sensitivity properties such as friction, impact and thermal ignition are significantly better than primary explosives. In 1974, it was found that the pyrotechnic mixture, titanium hydride/potassium perchlorate

Received: August 22, 2020; Accepted: September 26, 2020

Keywords and phrases: FOX-7, DADNE, titanium, explosive, density functional.

Copyright (C) 2021 Lemi Türker. This is an open access article distributed under the Creative Commons Attribution License, which permits unrestricted use, distribution, and reproduction in any medium, provided the original work is properly cited. 
$\left(\mathrm{TiH}_{2} / \mathrm{KClO}_{4}\right)$ was insensitive to initiation from an equivalent human body discharge. This electrostatic discharge (ESD) insensitivity included bulk, pressed and loaded forms of $\mathrm{TiH}_{2} / \mathrm{KClO}_{4}$. Subsequent ESD tests with $\mathrm{TiH}_{2} / \mathrm{KClO}_{4}$, using discharge voltages in excess of 40 kilovolts and no resistance in the ESD circuit have never initiated this pyrotechnic. Its upper voltage or energy for ESD ignition is not known [4].

Although, the transition metals of group IV are well known as potent pyrotechnic fuels, metal powders are susceptible to aging and pyrotechnic compositions containing them can be sensitive to unintended ignition by electrostatic discharge [5]. The effect of titanium hydride on detonation heat of RDX based explosives was studied [6]. The critical conditions for the reaction of particles of the transition metal titanium (Ti) dispersed during the detonation of long cylindrical explosive charges have been investigated experimentally [7]. For the Ti particles, a threshold particle diameter exists above which self-sustained particle reaction is not observed for charge diameters although some particle reaction occurs immediately behind the detonation front then rapidly quenches. For the smallest particles $(40 \mu \mathrm{m})$, the proportion of the conical particle cloud that reacts increases with charge diameter, suggesting that the reaction is a competition between particle heating and expansion cooling of the products.

Titanium alloys also have been in used long for armor applications [8]. Structural analysis of three-metal explosion joint: zirconium-titanium-steel was reported [9]. Titanium-tissue interface reaction was studied by Hanawa [10].

No one explosive molecule has all of the properties desired from the perspective of both performance characteristics and sensitivity properties. Some immense effort has been devoted to ameliorate or reach to desirable qualities such as insensitivity to handling (impact, spark and friction) stimuli and shock as well as high thermal stability [11]. On the other hand, FOX-7 (1,1-diamino-2,2-dinitroethylene, geminal-DADNE) which is an insensitive high explosive recently incorporated in various explosive formulations [11]. It is a push-pull type conjugated system which is beneficial for the creation of strong inter- and intra-molecular hydrogen bonds for stabilizing the molecule. Since, it was first synthesized by Latypov et al. [12], it has been the subject of many experimental investigations [13-25]. FOX-7 has a favorable oxygen balance and its decomposition produces some gaseous products. 

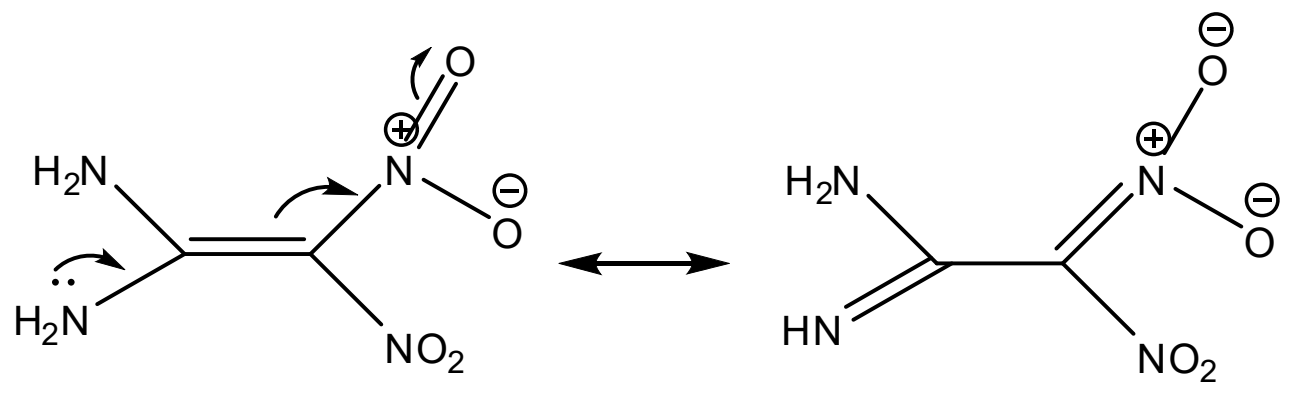

In the present study, effect of titanium on FOX-7 has been investigated at the molecular level within the constraints of density functional theory (DFT).

\section{Method of Calculation}

In the present study, firstly the initial structural optimizations of all the structures leading to energy minima have been achieved by using MM2 method followed by semiempirical PM3 self-consistent fields molecular orbital (SCF MO) method [26, 27] at the restricted level $[28,29]$. The subsequent optimizations were achieved at Hartree-Fock level using various basis sets hierarchically. Then, the structural optimizations were managed within the framework of density functional theory (DFT) [30, 31] at the levels of and B3LYP/6-311++G(2df,2p) [29, 32] and B3LYP/LANL2DZ [33] both of which are suitable for titanium atom. The exchange term of B3LYP consists of hybrid HartreeFock and local spin density (LSD) exchange functions with Becke's gradient correlation to LSD exchange $[31,34]$. The correlation term of B3LYP consists of the Vosko, Wilk, Nusair (VWN3) local correlation functional [35] and Lee, Yang, Parr (LYP) correlation correction functional [36]. Additionally, the vibrational analyses have been done. The total electronic energies are corrected for the zero point vibrational energy (ZPE). The normal mode analysis for each structure yielded no imaginary frequencies for the $3 \mathrm{~N}-6$ vibrational degrees of freedom, where $N$ is the number of atoms in the system. This indicates that the structure of each molecule corresponds to at least a local minimum on the potential energy surface. All these calculations were done by using the Spartan 06 package program [37].

\section{Results and Discussion}

Titanium atom has $1 \mathrm{~s}^{2} 2 \mathrm{~s}^{2} 2 \mathrm{p}^{6} 3 \mathrm{~s}^{2} 3 \mathrm{p}^{6} 3 \mathrm{~d}^{2} 4 \mathrm{~s}^{2}$ ground state electronic configuration possessing ionization potentials of $6.83,13.57,27.47,48.24$ and $99.8 \mathrm{eV}$, respectively 
for I-V oxidation states [38]. It has absolute electronegativity and chemical hardness values of $3.45 \mathrm{eV}$ and 3.37, respectively [39].

Figure 1 shows the optimized structures of the systems considered. As seen in the figure, both of the methods performed predict the cleavage of one of the $\mathrm{N}-\mathrm{O}$ bonds of FOX-7 molecule.

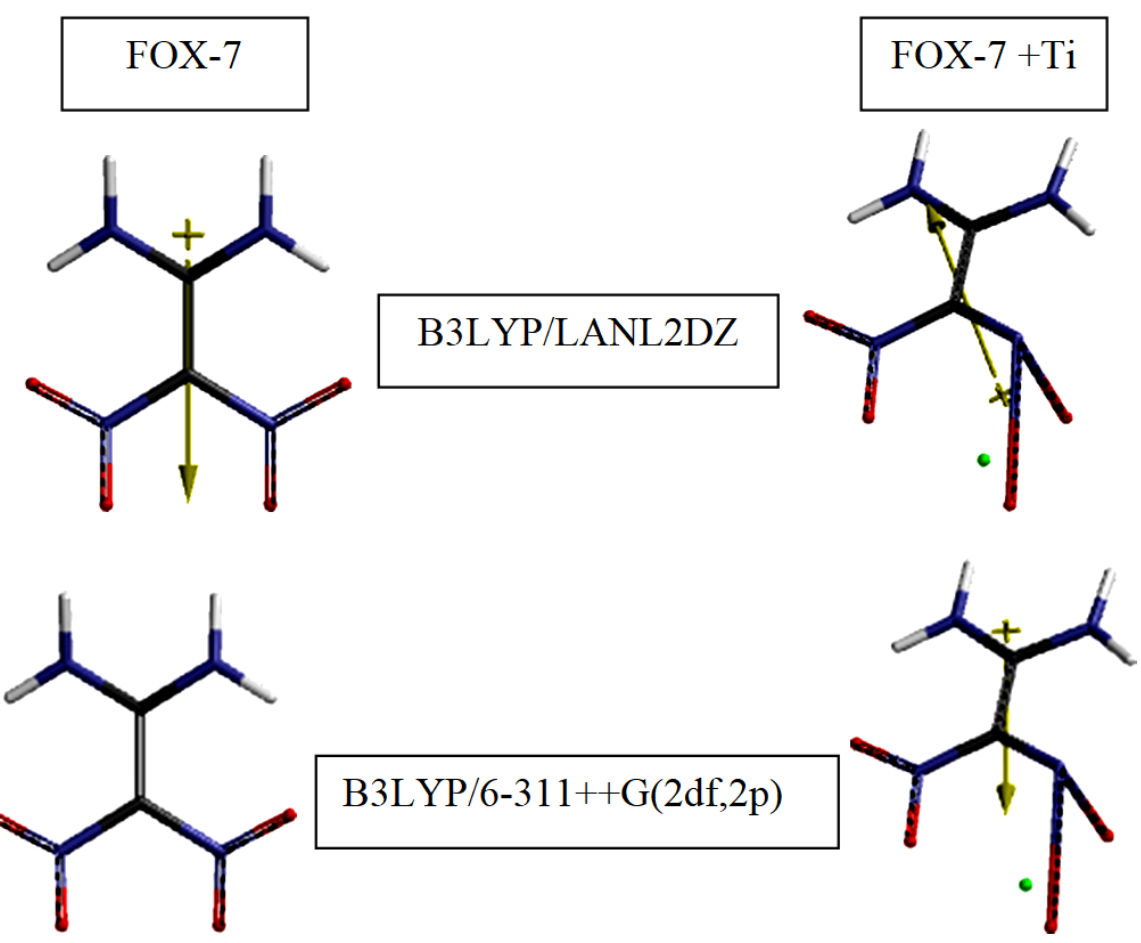

Figure 1. Optimized structures of the systems considered.

The ruptured N-O bond/distance is $3.217 \AA$ and $3.155 \AA$, respectively by B3LYP/LANL2DZ and B3LYP/6-311++G(2df,2p) optimizations. Although, some parallelism exists in appearance of the optimized structure of the composite in each case, the dipole moment vector reverses its direction.

Figure 2 shows the bond lengths/distances data of FOX-7 and the composite structure. Both of the methods employed predict comparable values for most of the bond lengths/distances. The carbon-carbon bond length in both of the structures do not vary much from each other but $\mathrm{C}-\mathrm{NO}_{2}$ bond lengths shrinks in the composite. Note that in nitroethylene that bond is reported as $1.322 \AA$ [40]. 

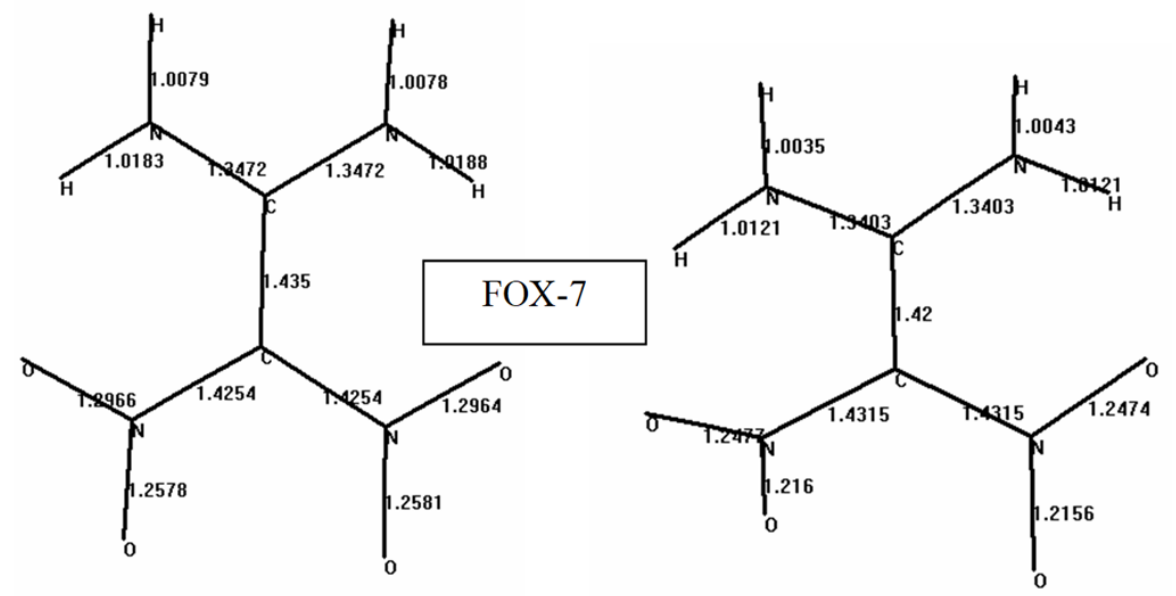

B3LYP/LANL2DZ

B3LYP/6-311++G(2df,2p)

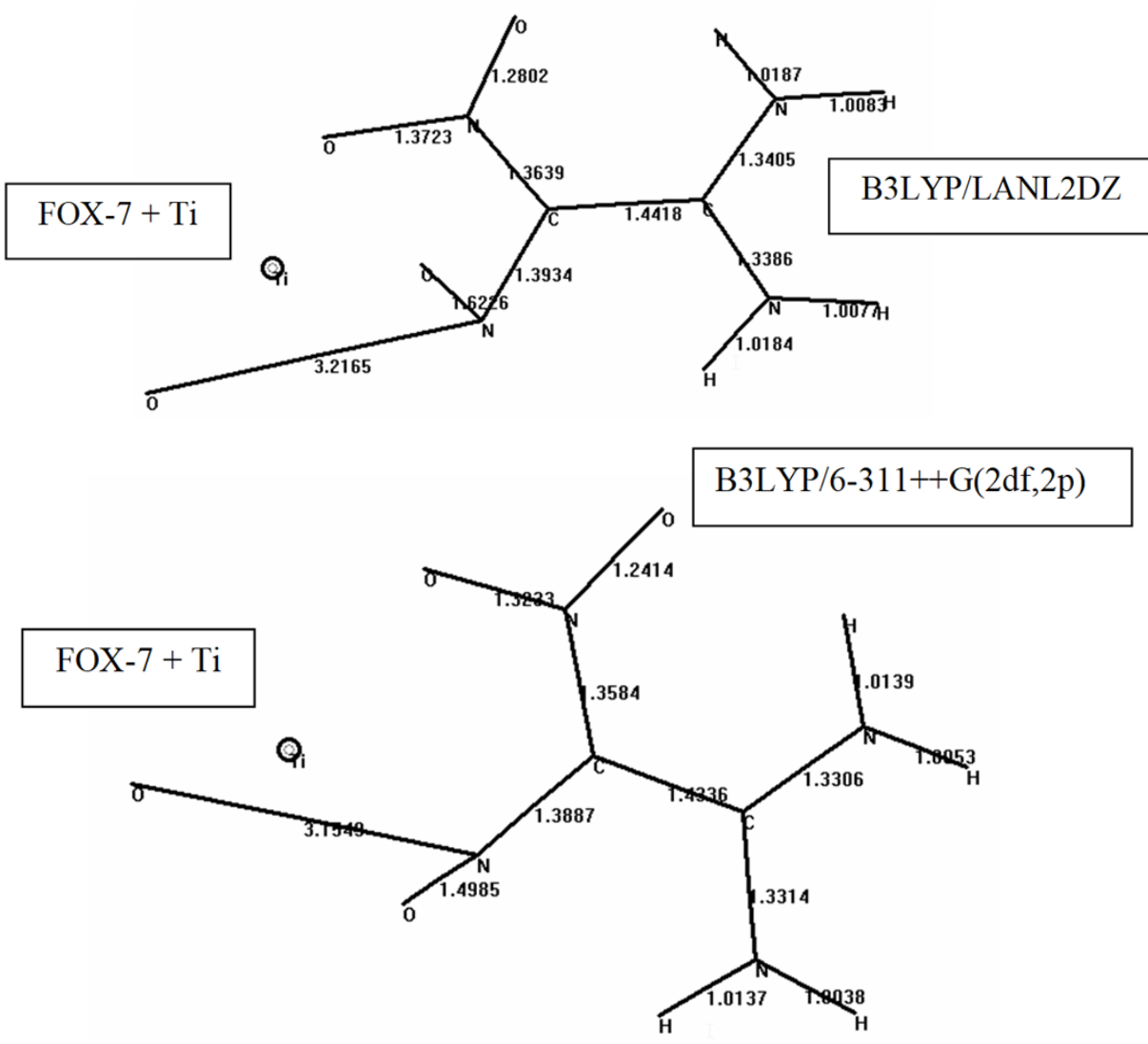

Figure 2. The calculated bond lengths/distances in FOX-7 and the composite. 
The titanium atom causes the cleavage of $\mathrm{N}-\mathrm{O}$ bond of FOX-7. A similar result reported by Tarasov et al. [41]. They observed the cleavage of C-F bond as a result of interaction of metallic titanium with a tetrafluoroethylene-vinylidene fluoride copolymer [41].

Figure 3 shows the electrostatic potential charges (ESP) on the atoms of the structure optimized systems considered. Note that the ESP charges are obtained by the program based on a numerical method that generates charges that reproduce the electrostatic potential field from the entire wavefunction [37]. The charges on FOX-7 are symmetrically distributed. In the Ti contained composite there is no symmetry at all in the charge distribution. The Ti atom possesses a high positive charge (6.63 esu) in the B3LYP/LANL2DZ optimized structure. Moreover, in both of the cases the nitrogen atom of the perturbed nitro group also possesses a negative charge and the oxygen atom of the broken $\mathrm{N}-\mathrm{O}$ bond leaves the system in negatively charged form.

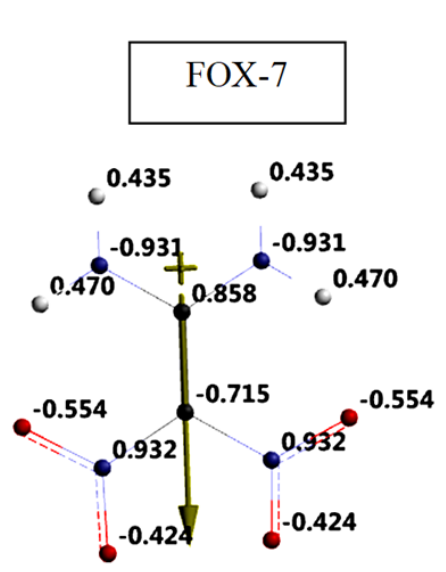

B3LYP/LANL2DZ

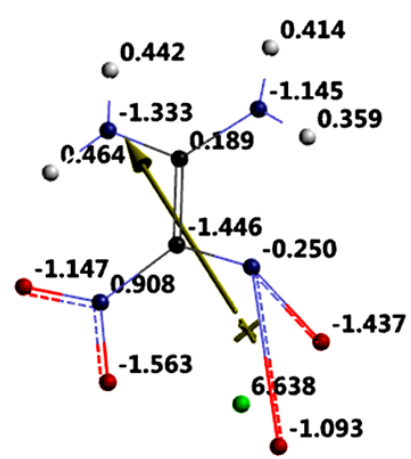

B3LYP/LANL2DZ

\section{FOX $-7+\mathrm{Ti}$}

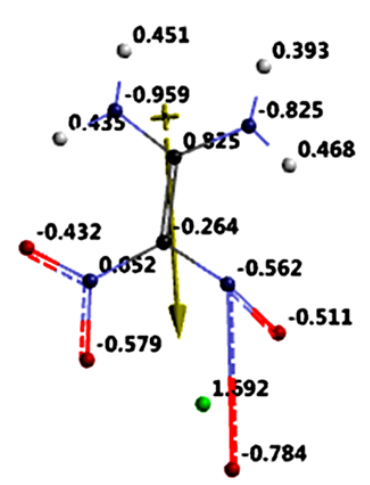

B3LYP/6-311++G(2df,2p)

Figure 3. ESP charges on the atoms of the systems considered.

Appearance of the electrostatic potential maps of the systems is shown in Figure 4 where red/reddish and blue/ green regions stand for negative and positive potential fields, respectively. 

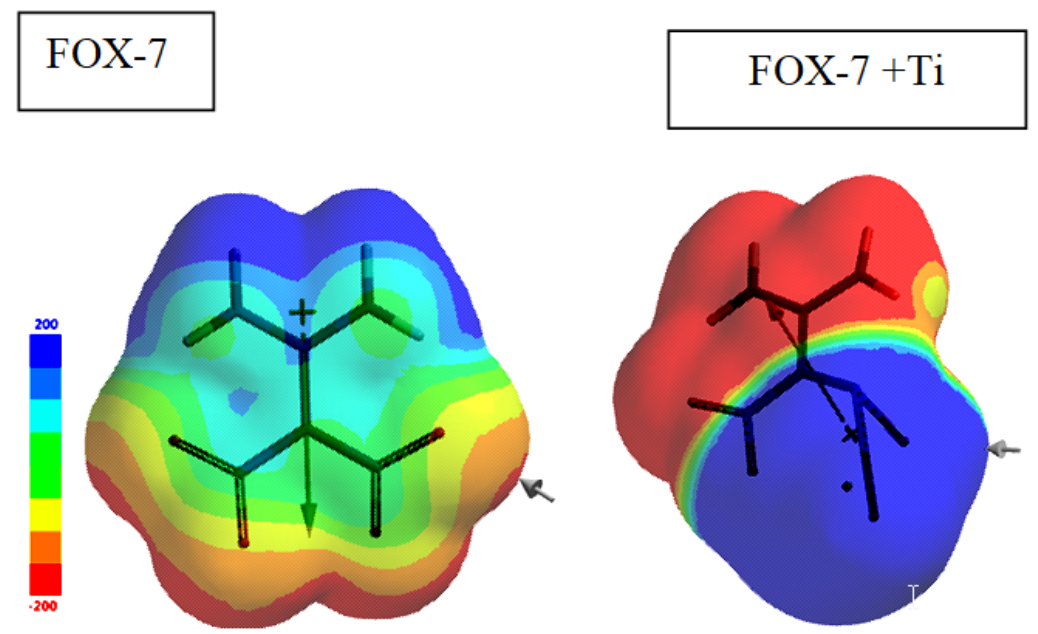

Figure 4. Electrostatic potential maps of the systems considered (B3LYP/LANL2DZ).

Table 1 shows various properties of the systems considered.

Table 1. Various properties of the systems considered.

\begin{tabular}{lccccc}
\hline System & Area & Volume & Ovality & $\begin{array}{c}\text { Dipole } \\
\text { moment }\end{array}$ & Polarizability \\
\hline *FOX-7 & 140.15 & 110.64 & 1.26 & 9.17 & 49.31 \\
*FOX-7+Ti & 160.50 & 124.24 & 1.33 & 44.64 & 51.35 \\
**FOX-7 & 138.64 & 109.43 & 1.25 & - & 49.14 \\
**FOX-7+Ti & 158.24 & 122.62 & 1.33 & 51.52 & 50.45 \\
\hline
\end{tabular}

*B3LYP/LANL2DZ, **B3LYP/6-311++G(2df,2p).

Table 2 displays the HOMO, LUMO energies and the interfrontier molecular orbital energy gap $(\Delta \varepsilon)$ values of the systems considered. The HOMO energy order is FOX-7 $<$ FOX-7+Ti by the both levels of calculations. A similar trend exists for the LUMO energies, whereas $\Delta \varepsilon$ values follow the order of FOX-7 $>$ FOX-7+Ti. Thus, the effect of Ti atom is that it raises both the HOMO and LUMO energy levels at unequal extents while decreasing the interfrontier molecular orbital energy gaps. This outcome is the indication of some electron population has been transferred from the titanium atom into the organic moiety. 
Table 2. The HOMO, LUMO energies and $\Delta \varepsilon$ values.

\begin{tabular}{lccc}
\hline System & HOMO & LUMO & $\Delta \boldsymbol{\varepsilon}$ \\
\hline *FOX-7 & -712.97 & -287.56 & 425.41 \\
$*$ FOX-7+Ti & -34.54 & 7.44 & 41.98 \\
$* *$ FOX-7 & -719.26 & -265.75 & 453.51 \\
$* *$ FOX-7+Ti & -590.43 & -237.19 & 353.24 \\
\hline
\end{tabular}

Energies in $\mathrm{kJ} / \mathrm{mol} .{ }^{*} \mathrm{~B} 3 \mathrm{LYP} / \mathrm{LANL} 2 \mathrm{DZ},{ }^{*} \mathrm{~B} 3 \mathrm{LYP} / 6-311++\mathrm{G}(2 \mathrm{df}, 2 \mathrm{p})$.

Figure 5 shows some of the molecular orbital energy levels of the systems. as seen in
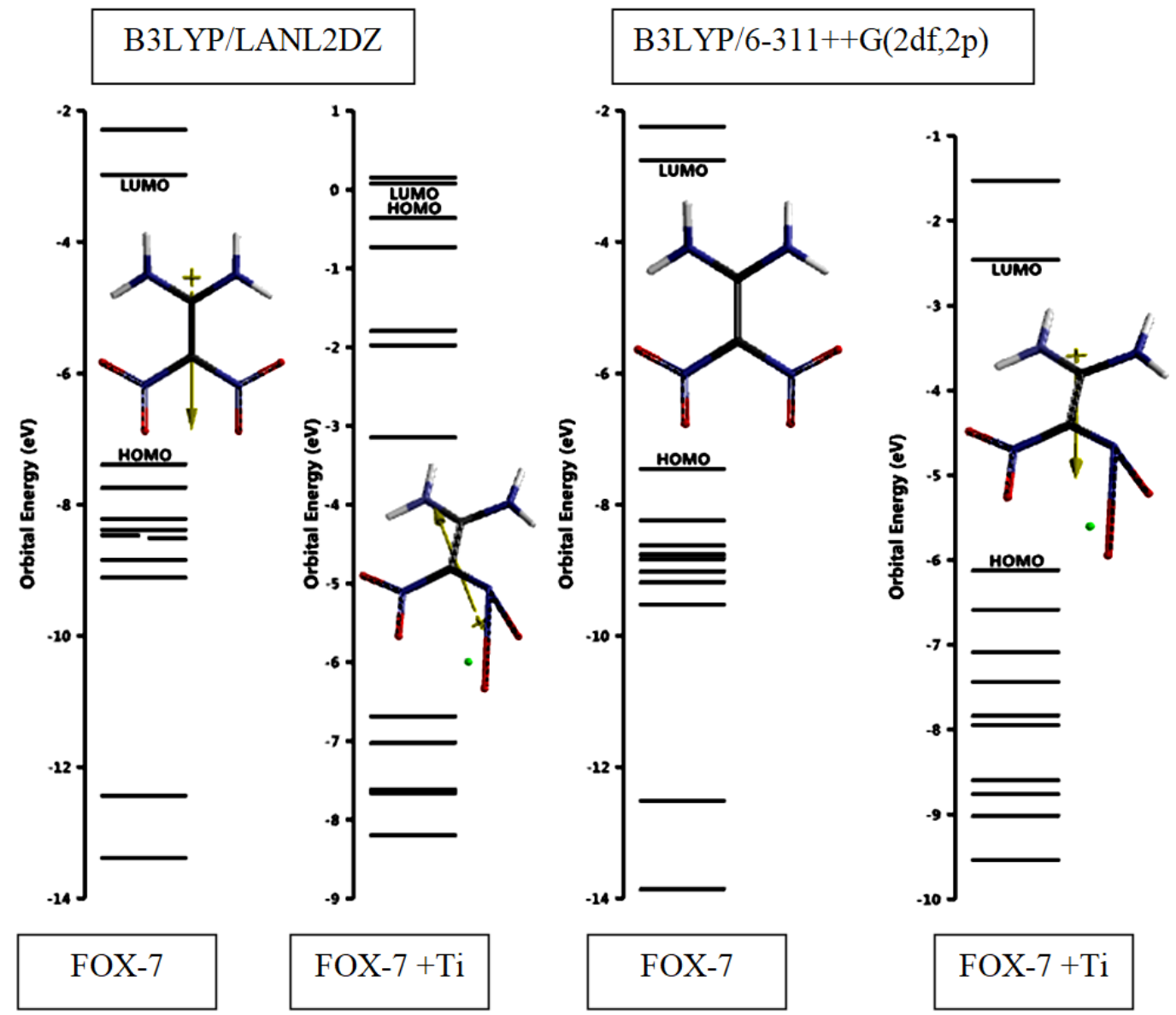

Figure 5. Some of the molecular orbital energy levels of the systems. 
the figure the presence of titanium atom narrows the interfrontier molecular orbital energy gap as compared to FOX-7 molecule. Note that LANL2DZ level of calculation for the composite system predicts nearly spaced LUMO and next LUMO (NLUMO) energy levels which possess positive value.

Figure 6 shows the HOMO and LUMO patters of the structures considered. FOX-7 has some $\pi$-symmetry which is highly perturbed by the titanium atom in the composite. The HOMO of the composite spreads over the nitro groups and the titanium atom. Whereas the LUMO resides on the amino groups of the FOX-7 moiety of the composite. In the LUMO pattern d-orbital contribution of titanium is discernable.

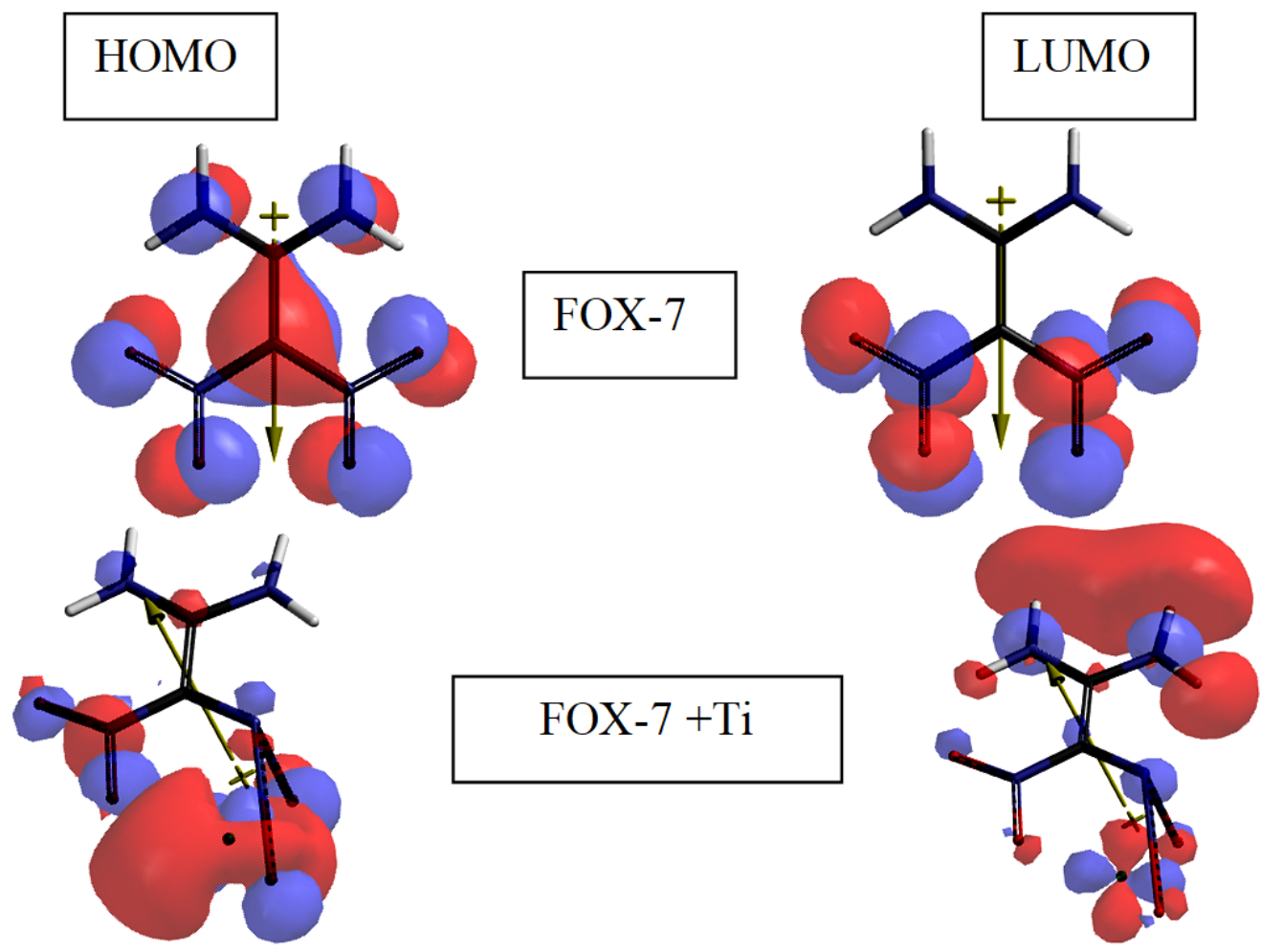

Figure 6. The HOMO and LUMO patterns (B3LYP/LANL2DZ).

Figure 7 shows the time-dependent density functional (TDDFT) UV-VIS spectra of the systems of present concern. As seen in the figure, both of the calculation methods predict some shift of the spectra towards the visible region (bathochromic effect) and emergence of new absorption in the visible part as the titanium atom interacts with FOX7 molecule. The bathochromic effect is due to the narrowing of interfrontier molecular 
energy gap in the presence of Ti atom compared to FOX-7 case. The emergence of a new absorption peak is the evidence of reshuffling of FOX-7 molecular orbitals by the titanium atom.
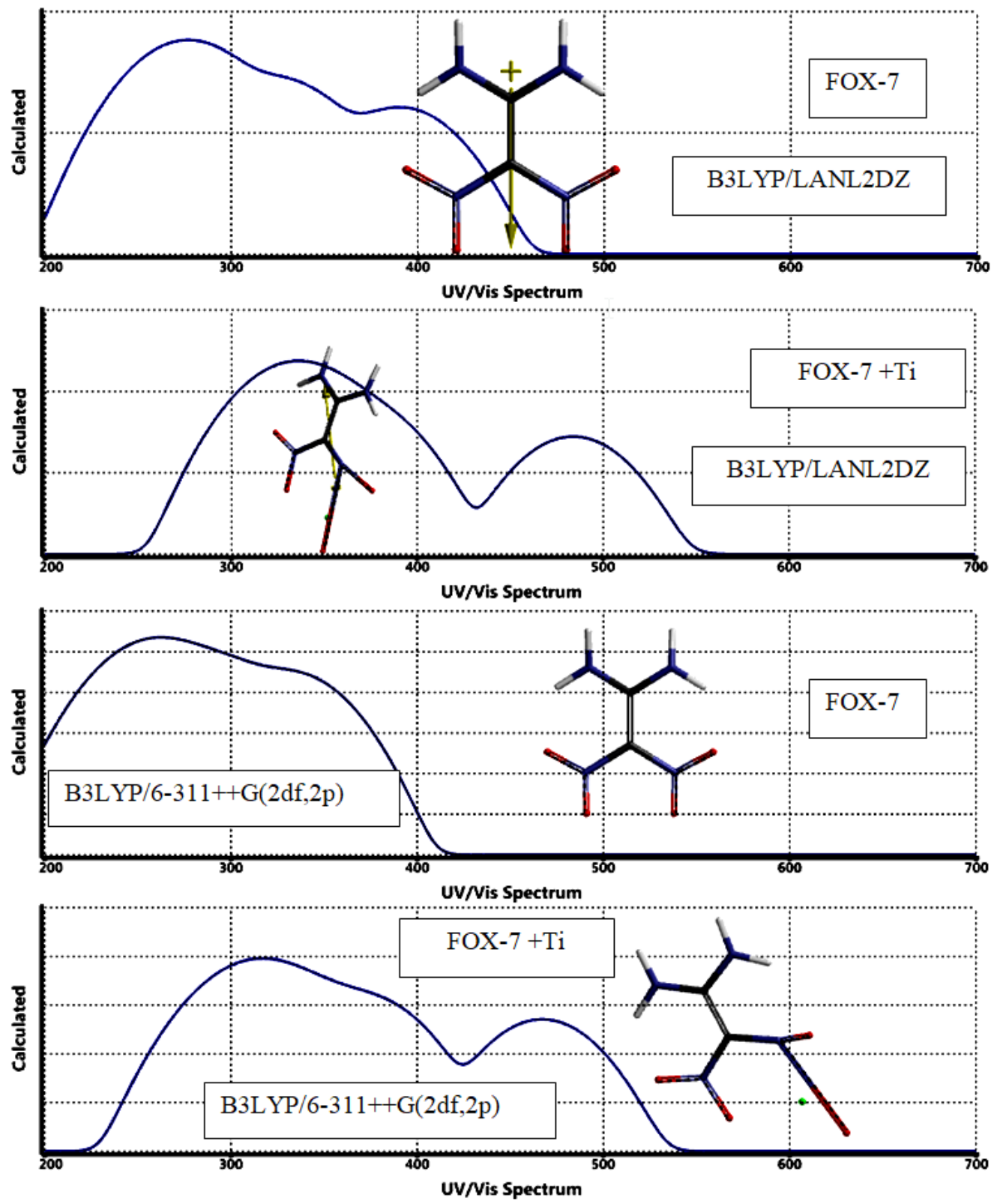

Figure 7. UV-VIS spectra of the systems. 
The narrowing of interfrontier molecular orbital gap indicates that the composite should be more sensitive to impact stimuli because $\Delta \varepsilon$ values are related to impact sensitivity in explosives [42, 43]. Namely, as the FMO energy gap $(\Delta \varepsilon)$ becomes less and less the impact sensitivity increases more and more.

Figure 8 shows the local ionization maps of FOX-7 and its titanium composite. In the local ionization potential map conventionally red regions on the density surface indicate areas from which electron removal is relatively easy, meaning that they are subject to electrophilic attack. On the other hand, regions having blue color represent areas where ionization is relatively difficult. Thus, the electron population transferred from titanium atom locates on the other nitro group which is red region of the map standing for the composite.
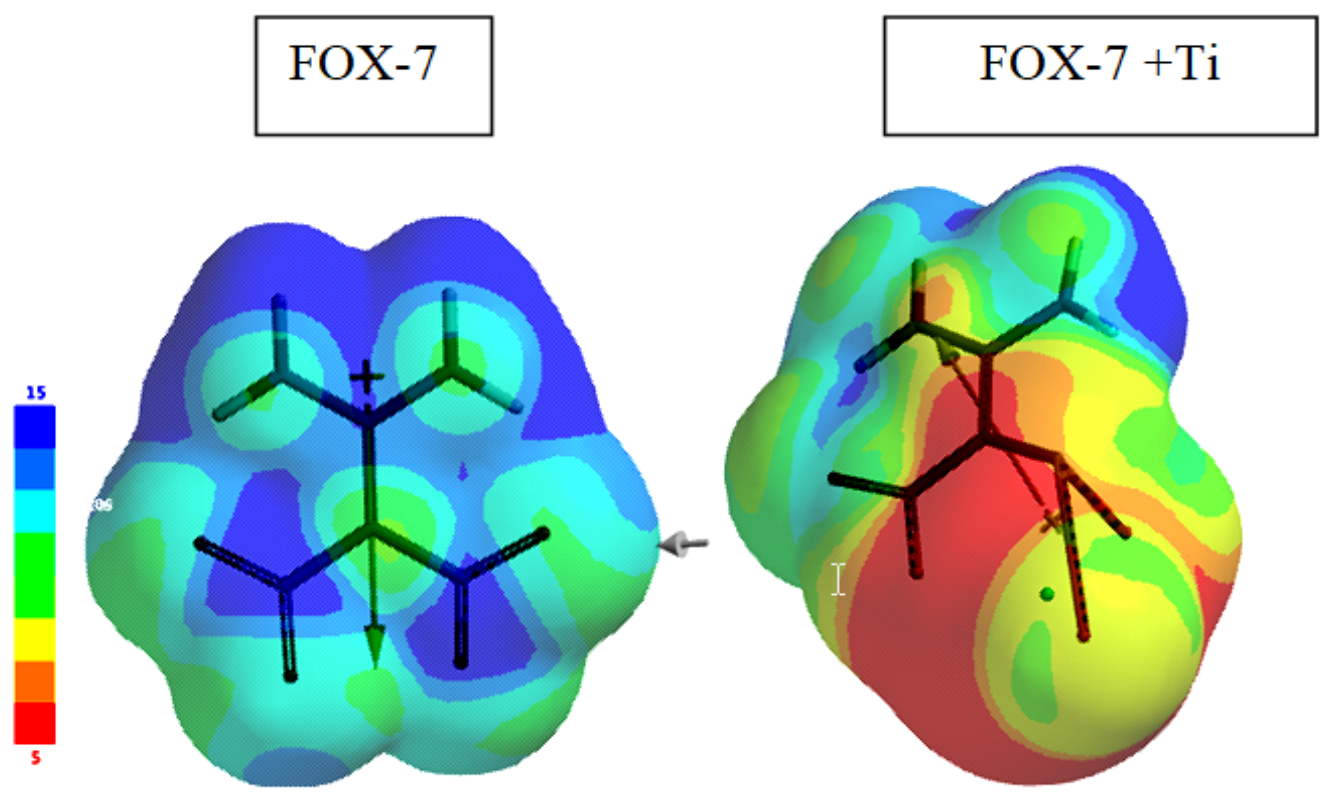

Figure 8. Local ionization potential maps (B3LYP/LANL2DZ).

Figure 9 shows the LUMO maps of the systems. A LUMO map displays the absolute value of the LUMO on the electron density surface. The blue color stands for the maximum value of the LUMO and the color red, the minimum value. Hence, a nucleophile attacks on the atom having the blue color. 

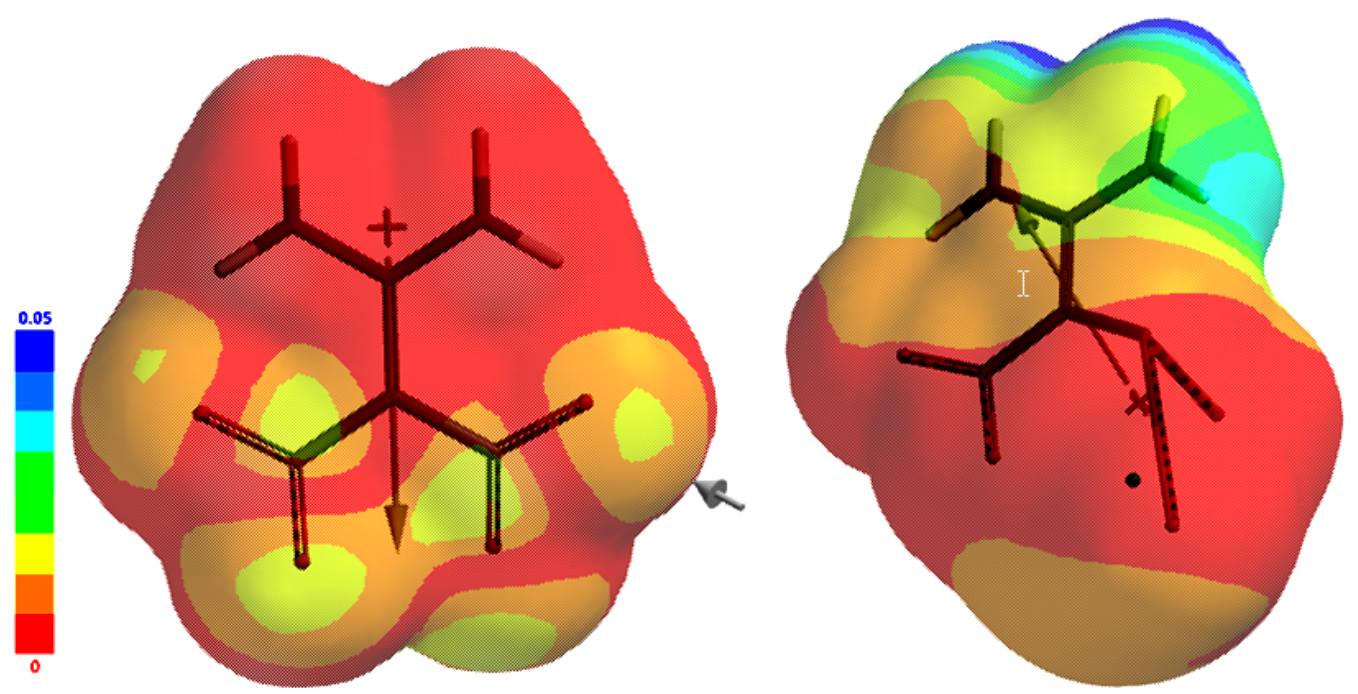

Figure 9. LUMO maps of the systems considered (B3LYP/LANL2DZ).

\section{Conclusion}

Within the limitations of the density functional theory at the applied levels of calculations on 1:1 composite of FOX-7+Ti has revealed that these two components are not compatible with each other. The titanium atom causes one of the N-O bonds of FOX7 to rupture. The composite in that form should be more sensitive to impact stimulus and aging effects. Since UV-VIS spectra of the composite exhibits bathochromic effect, absorption in the visible region, some color change is to accompany the rupture of the $\mathrm{N}$ $\mathrm{O}$ bond.

\section{References}

[1] D.N. Trifonov and V.D. Trifonov, Chemical Elements: How They Were Discovered, Moscow: Mir, 1982.

[2] A. Betekhtin, A Course of Mineralogy, Moscow: Mir,1964.

[3] M.S. Russel, The Chemistry of Fireworks, Cambridge: RSC Pub., 2009.

[4] T.M. Massis, J.W. Fronabarger and W.B. Sanborn, New explosive materials and pyrotechnic formulations with improved safety and sensitivity properties, United States Department of Energy under Contract DE-AC04-94AL85000. 14186c9f607e42b2fb2bb77edaf945a089b3.pdf 
[5] A.P. Shaw, R.K. Sadangi, J.C. Poret and C.M. Csernica, Metal-element compounds of titanium, zirconium, and hafnium as pyrotechnic fuels.

7de423ef045f1bd5d36e92331f5b34972e14.pdf

[6] S. Cudziło, W.A. Trzciński, J. Paszula, M. Szala and Z. Chyłek, Effect of titanium and zirconium hydrides on the detonation heat of RDX-based explosives - A comparison to aluminum, Prop. Explos. Pyrotech. 4(3) (2018), 280-285.

https://doi.org/10.1002/prep.201700237

[7] R. Lane, B. Craig and W. Babcock, Materials for blast and penetration resistance, The AMPTIAC Quarterly, Protecting People at Risk (special issue) 6(4) (2003), 39-45. https://p2infohouse.org/ref/34/33102.pdf

[8] D.L. Frost, M. Cairns, S. Goroshin and F. Zhang, Reaction of titanium and zirconium particles an cylindrical explosive charges, AIP Conference Proceedings 955(1) (2007), 781-784. https://doi.org/10.1063/1.2833240

[9] I. Samardzıc, Z. Kozuh and B. Matesa, Structural analysis of three-metal explosion joint: zirconium-titanium-steel, METABK 49(2) (2010), 119-122.

[10] T. Hanawa, Titanium-tissue interface reaction and its control with surface treatment, Front. Bioeng. Biotechnol. 7 (2019), Article 170.

https://doi.org/10.3389/fbioe.2019.00170

[11] P.R. Bowden, B.C. Tappan, M.M. Schmitt, R.W. Lebrun, M. Shorty, P.W. Leonard, J.P. Lichthardt, E.G. Francois and L.G. Hill, Synthesis, formulation and performance evaluation of reduced sensitivity explosives, AIP Conference Proceedings 1979 (2018), 100005. https://doi.org/10.1063/1.5044877

[12] N.V. Latypov, J. Bergman, A. Langlet, U. Wellmar and U. Bemm, Synthesis and reactions of 1,1-diamino-2,2-dinitroethylene, Tetrahedron 54(38) (1998), 11525-11536. https://doi.org/10.1016/S0040-4020(98)00673-5

[13] S. Karlsson, H. Ostmark, C. Eldsater, T. Carlsson, H. Bergman, S. Wallin and A. Pettersson, Detonation and sensitivity properties of FOX-7 and formulations containing FOX-7, 12th Int. Symp. Detonation, San Diego, California, August 11-16, 2002.

[14] B. Janzon, H. Bergman, C. Eldsater, C. Lamnevik and H. Ostmark, FOX-7 - A novel, high performance, low vulnerability high explosive for warhead applications, 20th Int. Symp. Ballistics, Orlando, Florida, September 23-27, 2002.

[15] Y.N. Matyushin, G.T. Afanas'ev, V.P. Lebedev, M.N. Mahov and V.I. Pepekin, TATB and FOX-7: thermochemistry, performance, detonability, sensitivity, 34th Int. Annu. Conf. ICT, Karlsruhe, Germany, June 24-27, 2003. 
[16] S. Cudziło and W. Kicinski, Synthesis and properties of DADNE (in Polish), Biuletyn WAT 53(2-3) (2004), 183-204.

[17] A.J. Bellamy, N.V. Latypov and P. Goede, Studies on the nitration of new potential precursors for FOX-7, New Trends Res. Energ. Mater., Proc. Semin., 7th, Pardubice, Czech Republic, April 20-22, 2004.

[18] Z. Chyłek, S. Cudziło, J. Błądek and S. Pietrzyk, Optimization of 1,1-diamino-2,2dinitroethene synthesis (in Polish), Biuletyn WAT 54(5-6) (2005), 19-16.

[19] S. Cudziło, Z. Chyłek and R. Diduszko, Crystallization and characterization of 1,1diamino-2,2-dinitroethene (DADNE) (in Polish), Biuletyn WAT 54(5-6) (2005), 5-18.

[20] S. Cudziło, Z. Chyłek and R. Diduszko, Crystallization and characterization of 1,1diamino-2,2-dinitroethene (DADNE), 36th Int. Annu. Conf. ICT, Karlsruhe, Germany, June 28-July 1, 2005.

[21] S. Cudziło and Z. Chyłek, 1,1-Diamino-2,2-dinitroethene (DADNE), a new high energetic and low sensitive explosive (in Polish), Wiadomości Chemiczne 60(11-12) (2006), 763791.

[22] W.A. Trzciński, S. Cudziło, Z. Chyłek and L. Szymańczyk, Investigation of sensitivity and detonation properties of FOX-7, 37th Int. Annu. Conf. ICT, Karlsruhe, Germany, June 27-30, 2006.

[23] M. Anniyappan, M.B. Talawar, G.M. Gore, S. Venugopalan and B.R. Ganghe, Synthesis, characterization and thermolysis of 1,1-diamino-2,2-dinitroethylene (FOX-7) and its salts, J. Hazard. Mater. B137 (2006), 812-819. https://doi.org/10.1016/j.jhazmat.2006.03.034

[24] W.A. Trzciński, S. Cudziło, Z. Chyłek and L. Szymańczyk, Determination of the expansion isentrope for detonation products of FOX-7, 38th Int. Annu. Conf. ICT, Karlsruhe, Germany, June 26-29, 2007.

[25] W.A. Trzciński, S. Cudziło, Z. Chyłek and L. Szymańczyk, Detonation properties of 1,1diamino-2,2-dinitroethene (DADNE), J. Hazard. Mater. 157 (2008), 605-612. https://doi.org/10.1016/j.jhazmat.2008.01.026

[26] J.J.P. Stewart, Optimization of parameters for semiempirical methods I. Method, $J$. Comput. Chem. 10 (1989), 209-220. https://doi.org/10.1002/jcc.540100208

[27] J.J.P. Stewart, Optimization of parameters for semi empirical methods II. Application, $J$. Comput. Chem. 10 (1989), 221-264. https://doi.org/10.1002/jcc.540100209

[28] A.R. Leach, Molecular Modeling, Essex: Longman, 1997.

[29] P. Fletcher, Practical Methods of Optimization, New York: Wiley, 1990. 
[30] W. Kohn and L. Sham, Self-consistent equations including exchange and correlation effects, J. Phys. Rev. 140 (1965), 1133-1138. https://doi.org/10.1103/PhysRev.140.A1133

[31] R.G. Parr and W. Yang, Density Functional Theory of Atoms and Molecules, London: Oxford University Press, 1989.

[32] C.J. Cramer, Essentials of Computational Chemistry, Chichester, West Sussex: Wiley, 2004.

[33] A. Abkari, I. Chaabane and K. Guidara, DFT (B3LYP/LanL2DZ and $\mathrm{B} 3 \mathrm{LYP} / 6311 \mathrm{G}+(\mathrm{d}, \mathrm{p}))$ comparative vibrational spectroscopic analysis of organicinorganic compound bis(4-acetylanilinium) tetrachlorocuprate(II), Physica E: Lowdimensional Systems and Nanostructures 81 (2016), 136-144.

https://doi.org/10.1016/j.physe.2016.03.010

[34] A.D. Becke, Density-functional exchange-energy approximation with correct asymptotic behavior, Phys. Rev. A 38 (1988), 3098-3100.

https://doi.org/10.1103/PhysRevA.38.3098

[35] S.H. Vosko, L. Wilk and M. Nusair, Accurate spin-dependent electron liquid correlation energies for local spin density calculations: a critical analysis, Can. J. Phys. 58 (1980), 1200-1211. https://doi.org/10.1139/p80-159

[36] C. Lee, W. Yang and R.G. Parr, Development of the Colle-Salvetti correlation-energy formula into a functional of the electron density, Phys. Rev. B 37 (1988), 785-789. https://doi.org/10.1103/PhysRevB.37.785

[37] SPARTAN 06, Wavefunction Inc., Irvine CA, USA, 2006.

[38] P.J. Durant and B. Durant, Introduction to Advanced Inorganic Chemistry, London: Longman, 1972.

[39] R.G. Pearson, Absolute electronegativity and hardness: application to inorganic chemistry, Inorg. Chem. 27(4) (1988), 734-740. https://doi.org/10.1021/ic00277a030

[40] L.V. Vilkov, V.S. Mastryukov and N.I. Sadova, Determination of the Geometrical Structure of Free Molecules, Moscow: Mir, 1983.

[41] A.V. Tarasov, A.S. Alikhanian, G.A. Kirakosyan and I.V. Arkhangel'skii, Chemical interaction of metallic titanium with a tetrafluoroethylene-vinylidene fluoride copolymer, Inorganic Materials 46(12) (2010), 1308-1312.

https://doi.org/10.1134/S0020168510120071 
[42] V. Anbu, K.A. Vijayalakshmi, R. Karunathan, A.D. Stephen and P.V. Nidhin, Explosives properties of high energetic trinitrophenyl nitramide molecules: A DFT and AIM analysis, Arabian Journal of Chemistry 12(5) (2019), 621-632.

https://doi.org/10.1016/j.arabjc.2016.09.023

[43] N.R. Badders, C. Wei, A.A. Aldeeb, W.J. Rogers and M.S. Mannan, Predicting the impact sensitivities of polynitro compounds using quantum chemical descriptors, Journal of Energetic Materials 24 (2006), 17-33. https://doi.org/10.1080/07370650500374326 